\title{
Hydrozirconation-Isomerisation. Reactions of Terminally Functionalised Olefins with Zirconocene Hydrides and General Aspects
}

\author{
Ulf Annby, ${ }^{*, a}$ Susanne Karlsson, ${ }^{*, a}$ Salo Gronowitz, ${ }^{a}$ Anders Hallberg, ${ }^{b}$ Jörgen Alvhäll \\ and Rolf Svenson
}

a Division of Organic Chemistry 1, Chemical Center, University of Lund, P.O.B. 124, S-221 00 Lund, Sweden and b Department of Organic Pharmaceutical Chemistry, Biomedical Center, Uppsala University, P.O.B. 574, S-751 23 Uppsala, Sweden

\begin{abstract}
Annby, U., Karlsson, S., Gronowitz, S., Hallberg, A., Alvhäll, J. and Svenson, R., 1993. Hydrozirconation-Isomerisation. Reactions of Terminally Functionalised Olefins with Zirconocene Hydrides and General Aspects. - Acta Chem. Scand. 47: $425-433$.

Hydrozirconation of internal aliphatic olefins, with terminal oxygen-, sulfur- or nitrogen-containing functionalities, has been studied. Internally unsaturated ethers, sulfides, a phenylsulfone and an ammonium iodide underwent substantial elimination of the functional group, after rearrangement of the zirconium moiety towards the carbon bearing the heteroatoms.

With aromatic olefins, acceptable yields of terminal alkylzirconiums (based on deuteriation) were usually difficult to achieve. One exception was the reaction of 1-phenyl-1-hexene with ' $\mathrm{Cp} * \mathrm{CpZr}(\mathrm{H}) \mathrm{Cl}$ ' $\left(\mathrm{Cp}^{*}=\eta^{5}-\mathrm{C}_{5} \mathrm{Me}_{5}\right)$. Pronounced cleavage of the methyl-sulfur bond occurred in the hydrozirconation of 1-(1-hexenyl)-2-thiomethylbenzene.

Results from deuterio- and hydro-zirconations of ordinary alkenes indicated dissociation of the metal hydride from the olefins during rearrangement.
\end{abstract}

Hydrometallation-isomerisation of internal olefins is a way of making unactivated methyl hydrogens accessible to substitution [eqn. (1)]. Among existing procedures, hydroalumination,,$^{1,2}$ hydroboration,,$^{3-6}$ or hydrozirconation ${ }^{7,8}$ seem to be methods of choice with respect to isomerisation. ${ }^{\dagger}$ Both hydroalumination and hydroboration require high temperatures for rearrangement to occur, which can cause side reactions. ${ }^{1,16}$ For hydroalumination, isomerisation towards the chain terminus is facilitated by the presence of catalysts, ${ }^{17-19}$ which may also be the case for hydroboration. Irrespective of whether the aluminium or boron approach is used, heteroatoms in the olefinic substrate [Y; eqn. (1)] can decrease the terminal selectivity. ${ }^{17,20-23}$

$$
\begin{gathered}
\mathrm{CH}_{3}-\left(\mathrm{CH}_{2}\right)_{m}-\mathrm{CH}=\mathrm{CH}-\left(\mathrm{CH}_{2}\right)_{n}-\mathrm{Y} \\
\stackrel{\text { 1) }[\mathrm{M}]-\mathrm{H}}{2) \mathrm{E}^{+}} \mathrm{E}-\left(\mathrm{CH}_{2}\right)_{m+n+3}-\mathrm{Y}
\end{gathered}
$$

\footnotetext{
* To whom correspondence should be addressed.

${ }^{+}$More or less hydridic species such as $[\mathrm{Si}]-\mathrm{H},[\mathrm{Ge}]-\mathrm{H}$, [Sn]-H, [Mg]-H and $\mathrm{ZnH}_{2}$ add to multiple bonds, but the addition to olefins usually has to be catalysed or initiated by other means. There seem to be very few reports on the formation of primary alkyl compounds in reactions of internal olefins with silanes, germanes or hydrides of tin, magnesium and zinc (Refs. 9-13). Exceptions have however appeared, where silanes with internal alkenes give terminal alkylsilicon compounds (see for instance Refs. 14 and 15).
}

Schwartz and coworkers reported the hydrozirconation procedure to be a very facile method of isomerisation under mild conditions [eqn. (2) ]. ${ }^{7}$ They also showed that the organometallic products (like aluminium and boron alkyls) were useful in organic synthesis. The number of different functionalities that can be introduced by cleavage of the $\mathrm{C}-\mathrm{Zr}$ bond has increased in recent years. $^{8,24-27}$

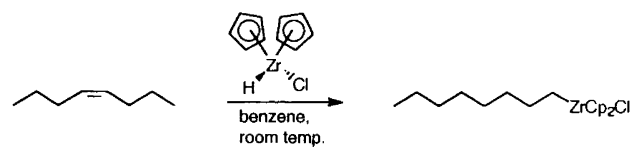

Since our aim was to use derivatives of unsaturated fatty acids, occurring naturally in large amounts, for the preparation of $\alpha, \omega$-difunctionalised compounds (which may also be prepared from internal acetylenes bearing a terminal heteroatom-containing substituent ${ }^{28}$ ), we considered hydrozirconation to be an attractive method. Furthermore, we wished to explore the influences of various functionalities on migration of the metal. Studies on aromatic olefins were also undertaken, knowledge of the hydrozirconation of such substrates was very limited at the initial stage of our work.

In a very recent review on hydrozirconation, ${ }^{8}$ most of our work is not included. We now summarise our 
results, which show some important limitations of hydrozirconation. Finally, a few general comments on hydrozirconation-isomerisation are made.

\section{Results and discussion}

The regiochemical outcome of rearrangement was chiefly established by ${ }^{2} \mathrm{H}$ NMR spectroscopy after deuteriolysis of the hydrozirconation mixtures. The deuterium content was determined by ${ }^{2} \mathrm{H}$ NMR or MS analyses. Reported yields were, if not stated otherwise, determined by GLC in combination with MS.

\section{Hydrozirconation of long-chain functionalised aliphatic} olefins. We set out to examine derivatives of the readily available oleic and erucic acids. Acids are reduced by $\mathrm{Cp}_{2} \mathrm{Zr}(\mathrm{H}) \mathrm{Cl}$, but can be converted into the corresponding oxazolines, which are inert towards reduction. Attempts to prepare aldehydes from a long-chain internally unsaturated oxazoline through hydrozirconation and subsequent reaction with carbon monoxide were unsuccessful. In contrast, a shorter-chain oxazoline, having a terminal double bond, could be $\omega$-formylated. The resulting aldehyde was, however, only stable in solution, and therefore we turned to hydroxylating reagents for cleavage of the $\mathrm{C}-\mathrm{Zr}$ bond. ${ }^{29}$

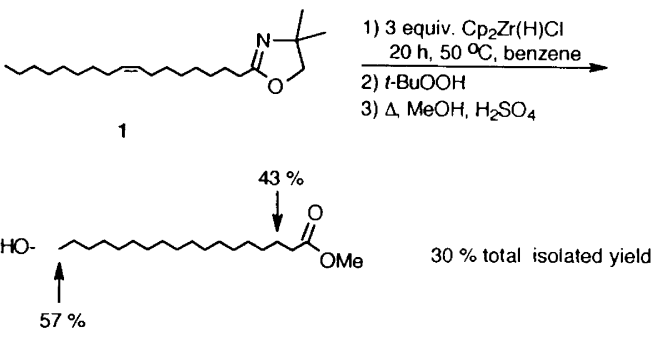

Hydrozirconation of oleic [1, eqn. (3)] and erucic acid oxazolines gave $\beta$ - and $\omega$-hydroxylated compounds after oxidation of intermediate alkylzirconiums. ${ }^{29}$ The formation of the $\beta-\mathrm{OH}$ isomer indicated stability of its zirconium precursor. Stabilisation is presumably due to coordination of oxygen (or nitrogen) to oxophilic zirconium. ${ }^{30-34}$

When deuterium oxide was used for cleavage of the $\mathrm{C}-\mathrm{Zr}$ bonds, yet another positional isomer could be observed $[\alpha-D$; eqn. (4) $] .{ }^{35}$ The entire process was also
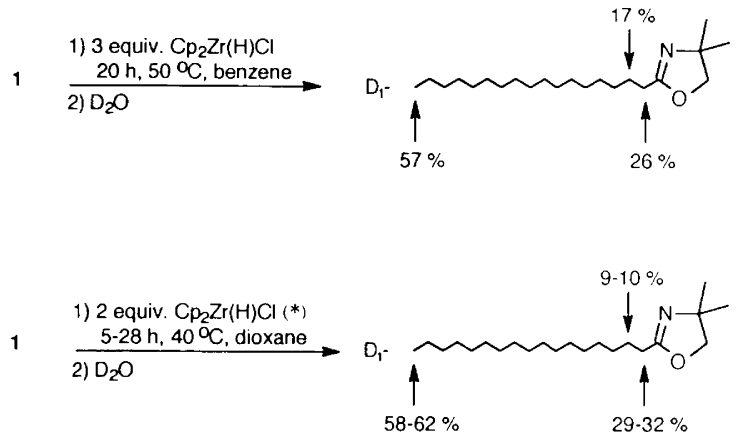

(*) Generated in situ. carried out with the oxazoline of hexanoic acid. This control experiment showed no deuterium incorporation. ${ }^{36}$ All attempts to oxidize $\alpha$-zirconium intermediates, obtained from short-chain $\alpha, \beta$-unsaturated oxazolines, to the corresponding $\alpha$-hydroxy compounds, failed. ${ }^{36}$ Clearly, caution must be used when comparing the regiochemical outcome of reactions in which different electrophiles have been utilised. Regioselectivity, with respect to the $\omega$-deuteriated isomer, was not improved using THF as the solvent.

The disappearance of unsaturated material was relatively rapid in dioxane (compared with when benzene or toluene were used as solvents) at a slightly elevated temperature $\left(40^{\circ} \mathrm{C}\right) .{ }^{35}$ Ether and hexane were not appropriate as solvents. ${ }^{29}$ With long-chain substrates, 2 equivalents of the reagent were necessary to achieve complete conversion in dioxane.

Small structural modifications of the protective group cause alterations of the regiochemistry [eqns. (5) and (6) $].{ }^{35}$ Moreover, the position of the double bond influences the composition of deuteriated products. ${ }^{36}$
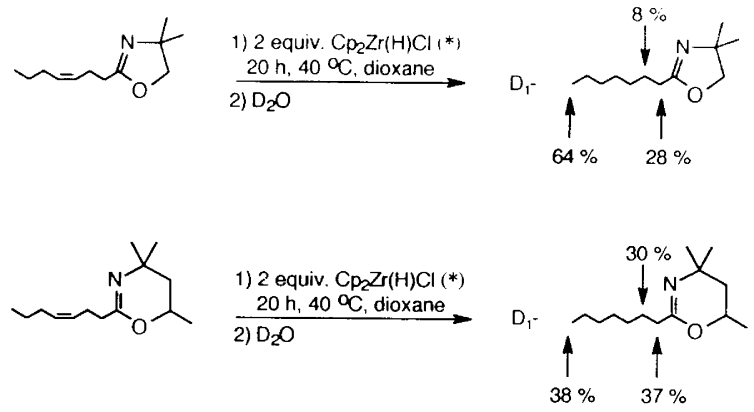

(*) Generated in situ.

The oxazolines shown in eqn. (7) are mainly hydrogenated upon treatment with $[\mathrm{Zr}]-\mathrm{H}$ and subsequent deuteriolysis. ${ }^{36}$ The reason for this is not understood. Other $\alpha, \beta$-unsaturated oxazolines did not show this behaviour under the same conditions. However, at higher temperatures $\left(\geqslant 50^{\circ} \mathrm{C}\right)$ hydrogenation, as well as decomposition of the reagent, can become a major problem. $^{29,37,38}$
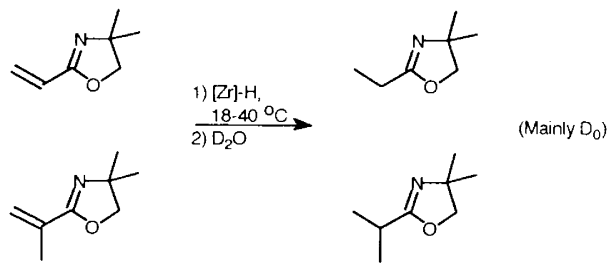<smiles>C=C(C)C1=NC(C)(C)CO1</smiles>

The investigations so far showed that complete regioselectivity was not easily achieved, and called for more experimentation with different functionalities. Our interest was turned to amines, ethers and sulfurcontaining compounds derived from oleic acid.

Hydrozirconation results obtained with oleyl amines 2a-c are shown in Fig. $1{ }^{39}$ As before, use of dioxane 


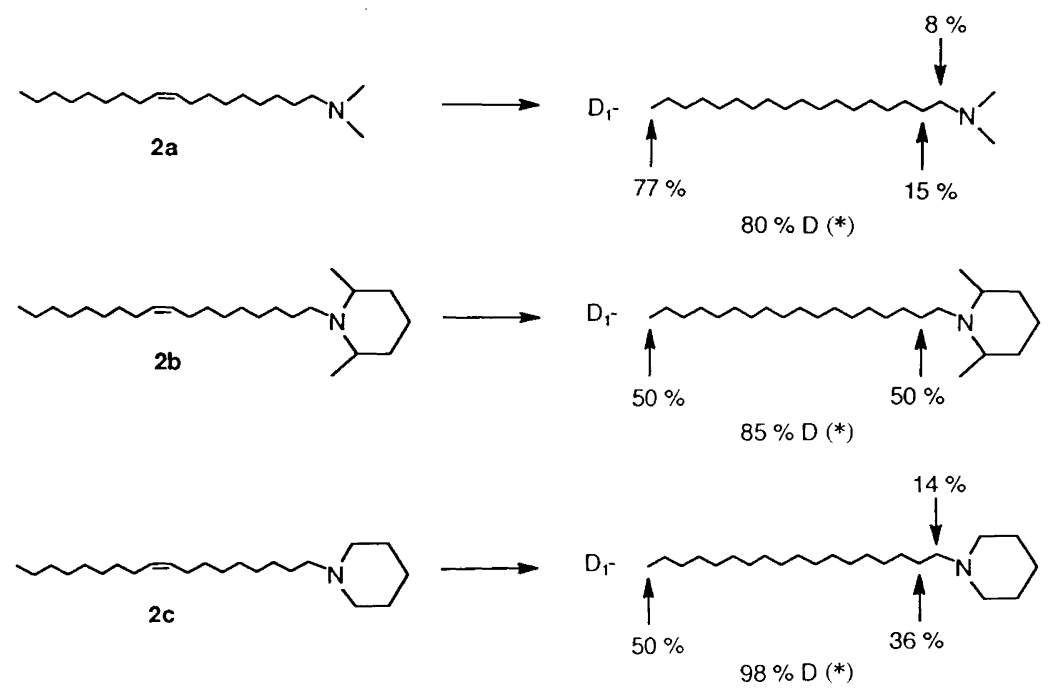

Fig. 1. * All reactions were run in dioxane at $40^{\circ} \mathrm{C}$ for $22-24 \mathrm{~h}$ with 3 equivalents of $[\mathrm{Zr}]-\mathrm{H}$ (generated in situ). Deuteriated yields are related to total isolated yields of amines $(40-70 \%)$, since unconsumed olefinic amines were difficult to separate from saturated ones.

proved advantageous. It is reasonable to assume that zirconium-heteroatom interactions in intermediate 1and 2-zirconocenyl species are responsible for the unsatisfactory selectivity. That the proportion of $\omega$-zirconium intermediate actually differs significantly when using amine $\mathbf{2 a}$, compared with $\mathbf{2} \mathbf{b}$ and $\mathbf{2} \mathbf{c}$, is not certain, since the degree of deuteriation differs somewhat in these cases, and by-products (although formed to a limited extent) were obtained.

A considerable amount of cleavage product was afforded by (Z)-9-octadecenyl trimethylammonium iodide [eqn. (8) ], under the conditions used for amines. ${ }^{39}$

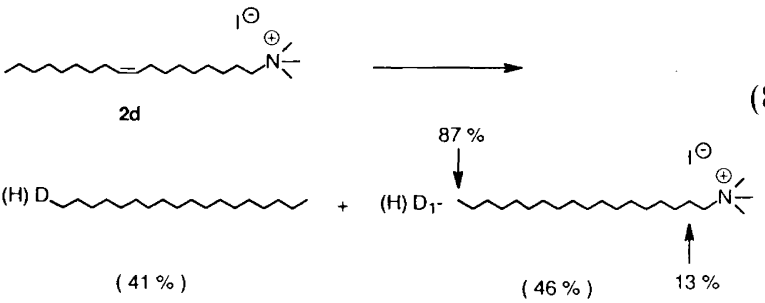

When the oleyl ethers $3 \mathbf{a}-\mathbf{c}$ were subjected to this reaction $\left(20 \mathrm{~h}, 40-45^{\circ} \mathrm{C}, 3\right.$ equivalents of in-situ generated
$[\mathrm{Zr}]-\mathrm{H})$, migration towards the functional group also resulted in $\beta$-elimination (Fig. 2). ${ }^{40}$ Although we never isolated the zirconium alkoxides or 1-octadecene, the occurrence of this type of elimination has been confirmed by others. ${ }^{30,41}$ Neither the saturated analogue of $\mathbf{2 d}$, nor that of $3 \mathbf{b}$, underwent cleavage when treated with the zirconium hydride under identical conditions. With (Z)-9-octadecenyl tert-butyldimethylsilyl ether [i.e., when $\mathrm{R}$ in Fig. 2 is $-\mathrm{Si}(\mathrm{Me})_{2}$-tert-Bu] elimination also occurred to a certain extent, but in another fashion, producing stearyl alcohol.

It was also of interest to examine the reactions of sulfurcontaining substrates, and to compare their reactivity with the ethers. Here too, substantial elimination was observed [eqn. (9)], to give $33-56 \%$ of octadecane. ${ }^{42}$

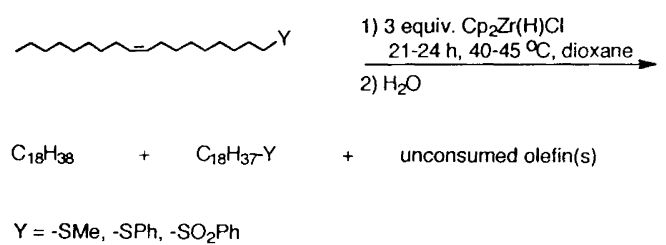

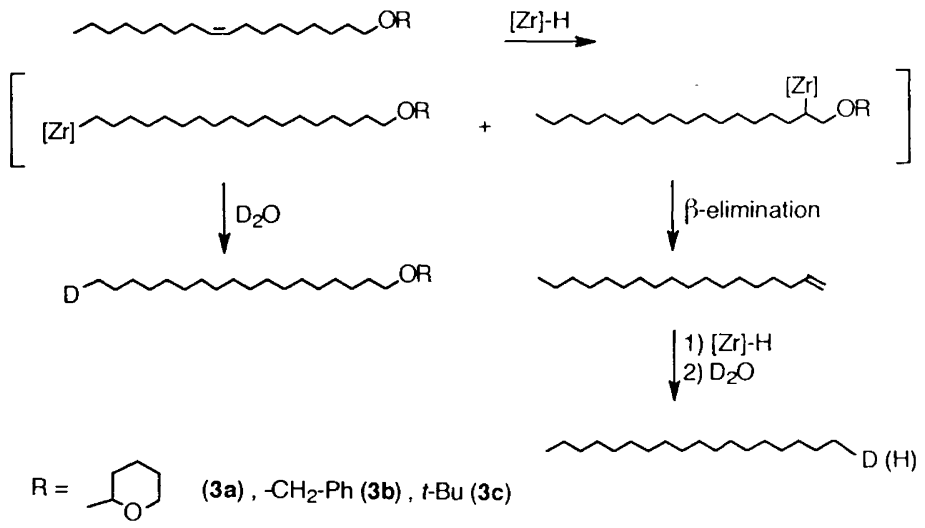

Fig. 2. 
Proton donors react with the metal hydride, one equivalent being wasted when oleyl alcohol is subjected to hydrozirconation. Only limited cleavage of the functional group was seen here. ${ }^{43}$ The reason for this is probably trapping of the zirconium moiety at the $\gamma$-position (as indicated by $\gamma$-deuteriation) by the formation of a five-membered cyclic intermediate, in which zirconium is connected to oxygen.

Once again it was shown that the apparent regiochemistry was dependent on the electrophile. The $\omega: \gamma$ ratio was $62-68: 32-38$ and $43-50: 50-57$ when deuterium oxide or bromine was used, respectively. Oleyl alcohol and its lithium salt give very similar product compositions after hydrozirconation-deuteriolysis. ${ }^{43}$

In summary, hydrozirconation-isomerisation does not seem to be an effective way of producing long-chain, doubly functionalised compounds from derivatives of naturally occurring fatty acids. It may also prove difficult to apply this synthetic scheme to short-chain heteroatomcontaining systems other than oxazolines (which also give products of mixed composition ${ }^{35.36}$ ), unless some variation is introduced, e.g., modification of the reagent. A few attempts were made in this direction (Section III).

It should be mentioned that very long-chain alkenes, on the other hand, are synthetically useful substrates 37,44 when using the $\mathrm{Cp}_{2} \mathrm{Zr}(\mathrm{H}) \mathrm{Cl}$ reagent (Fig. 3).

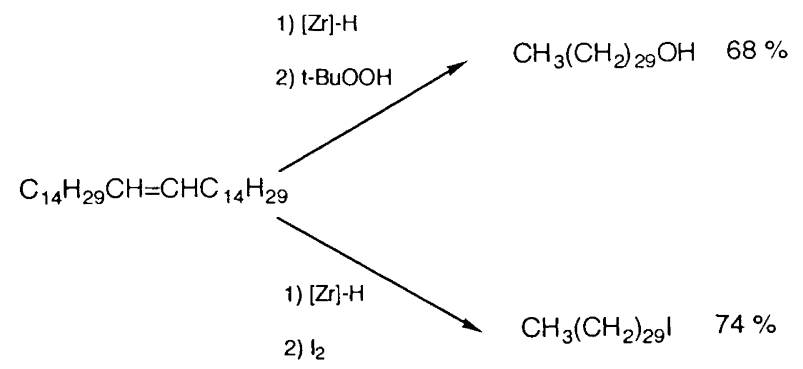

Fig. 3.

II. Hydrozirconation of aromatic olefins. We turned our attention to the substitution of alkenes with a terminal aromatic function. Reactions of $\mathrm{Cp}_{2} \mathrm{Zr}(\mathrm{H}) \mathrm{Cl}$ (generated in situ, if not otherwise stated) with subtrates 4-9 were initially examined with the aim of preparing zirconium derivatives such as $10 .{ }^{45}$ First, 1-phenyl-1-hexene (4) was
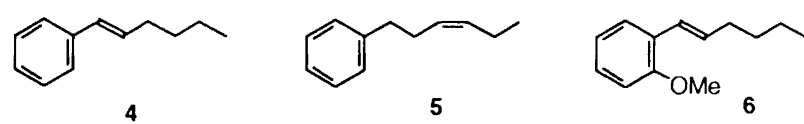

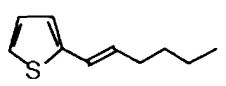

7<smiles>CCCCC=CC[123I]</smiles>

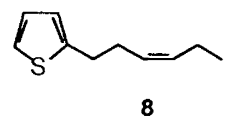

$\underline{[\mathrm{Zr}]-\mathrm{H}}$

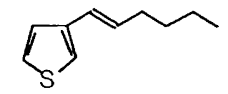

9

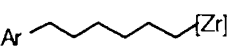

10 chosen. Compounds of this type are readily available from various coupling reactions.
Dioxane was used as the solvent throughout the entire study discussed in this section. The reaction of $\mathbf{4}$ is slow and requires somewhat elevated temperatures. It should be mentioned that all comparisons between rates of reaction of aromatic olefins are based on arylalkane formation (upon quenching) within $1-10 \mathrm{~h}$. As can be seen in eqn. (10), the benzylic isomer $(\alpha)$ predominated almost exclusively at room temperature, which is in agreement with Gibson's findings ${ }^{46}$ (this similar study appeared in the literature during the course of our work ${ }^{45}$ ). That a major part of the metal is actually directed towards the $\alpha$-carbon during initial addition at $20-25^{\circ} \mathrm{C}$, is indicated by the deuterium distribution in the phenylhexane formed by reaction of 4 with $\mathrm{Cp}_{2} \mathrm{Zr}(\mathrm{D}) \mathrm{Cl}$ (isolated) and subsequent hydrolysis: $[\beta-D /(\alpha-D+\beta-D)] \times 100=93 \%]^{*}$ [compare eqn. (10)].

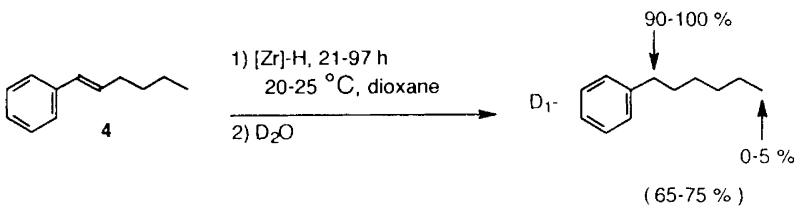

At $60^{\circ} \mathrm{C}$, good $\omega$-selectivity was achieved, but the yield of deuteriated phenylhexane decreased owing to competing hydrogenation ${ }^{45}$ (thermal decomposition ${ }^{37,38}$ ).

The unconjugated olefin 5 reacted much faster than 4 at room temperature, but even at $45^{\circ} \mathrm{C}$ the terminal selectivity was quite unsatisfactory.

The deuterium distribution with olefin 6 was not appreciably different from that found using 4 under the same conditions $\left(20-45^{\circ} \mathrm{C}\right)$.

Several examples of useful synthetic transformations of the thiophene nucleus are found in the literature. ${ }^{50}$ These can in principle be used for preparative purposes after hydrozirconation-functionalisation. We therefore decided to study the reaction of substrates 7-9 with the zirconium hydride. Heteroaromatic olefins 7 and 8 both reacted more slowly than the corresponding phenylhexenes. ${ }^{45}$ For 7 and 9 competing hydrogenation was extremely pronounced even at room temperature, resulting in hexylthiophenes with only $10-30 \%$ and

\footnotetext{
* That this labelling pattern reflects initial addition requires that the kinetic isotope effect $\left(k_{\mathrm{H}} / k_{\mathrm{D}}\right)$ for $\beta$-elimination is of such a magnitude, that the possible $\beta-\mathrm{Zr} \rightarrow \alpha-\mathrm{Zr}$ (or $\alpha \rightarrow \beta$ ) rearrangement does not lead to pronounced scrambling of $D$ between these positions. For reactions in which other transition-metal alkyls undergo $\beta-\mathrm{H}$ elimination to give alkenes, $k_{\mathrm{H}} / k_{\mathrm{D}}$ was found to be in the range 2-3, irrespective of whether the $\beta$-elimination was considered to be the rate-determining step, or not (Refs. 47 and 48). $\mathrm{PhCH}(\mathrm{D}) \mathrm{CH}_{2}[\mathrm{Zr}]$ and $\mathrm{PhCH}[\mathrm{Zr}] \mathrm{CH}_{2}$ (D) (obtained from styrene and $[\mathrm{Zr}]-\mathrm{D}$ ), without being in fast equilibrium with each other, both give the corresponding $D_{0}, D_{2}$ and $D_{3}$ analogues, i.e., $\mathrm{PhCH}_{m}(\mathrm{D})_{2-m} \mathrm{CH}_{2}[\mathrm{Zr}](m=0-2)$ and $\mathrm{PhCH}[\mathrm{Zr}] \mathrm{CH}_{n}(\mathrm{D})_{3-n}$ $(n=0-3)$. This was not observed with 1-phenyl-1-propene or 1-phenyl-2-propene (Ref. 49). Nevertheless, the $\alpha$-D: $\beta$-D ratio after deuteriozirconation-hydrolysis of 4 should not be affected in any case.
} 
$5-10 \%$ deuterium, respectively. At higher temperature $\left(45^{\circ} \mathrm{C}\right)$, larger amounts of hexylthiophenes were formed, but with no measurable degree of deuteriation. ${ }^{\dagger}$ In contrast, 2-[(Z)-3-hexenyl $]$ thiophene $(8)$ can be converted into 2-hexylthiophene with good terminal selectivity [eqn. (11)].

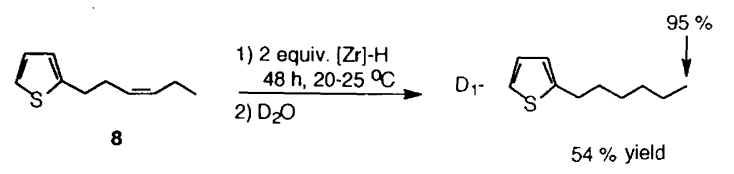

In order to determine the significance of the presence of sulfur, with respect to hydrogenation of hexenylthiophenes (hydrogenation did not depend on added thiophene during the hydrozirconation of 4), we used olefin 11 as the substrate [eqn. (12)], ${ }^{52}$ and compared it with the methoxy analogue 6 which reacted without such pronounced reduction.

At $20-25^{\circ} \mathrm{C}$ the reaction of 11 was very sluggish. When the temperature was raised to $45^{\circ} \mathrm{C}$, the reaction took a totally unexpected course [eqn. (12); sometimes other unknown products were also found]. The disulfide 14 was formed on exposure of the deuteriolysed reaction mixture to air. The extent of deuterium incorporation was low in products 12 and $\mathbf{1 3}$.
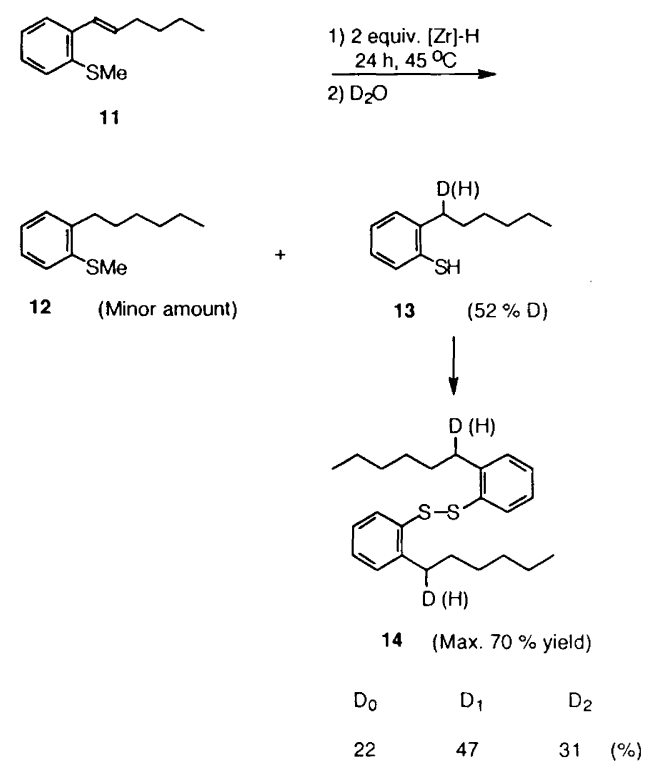

After treatment of 12 [eqn. (12)] with $\mathrm{Cp}_{2} \mathrm{Zr}(\mathrm{H}) \mathrm{Cl}$ (isolated), the aromatic compound was recovered unchanged. Moreover, the addition of thioanisole to solutions of preformed phenylethylzirconiums was not detrimental to the organometallics (based on deuterium content in ethylbenzene). The presence of sulfur in the vicinity of the double bond, as in 11, seems thus crucial, both to induce cleavage of the $\mathrm{C}-\mathrm{S}$ bond and to hydrogenation.

\footnotetext{
${ }^{+}$We obtained no evidence of a ring-opening reaction similar to that known for, e.g. 2-thenyllithium; cf. Ref. 51.
}

For compounds 7,9 and 11, results pointed towards the hydride and $\mathrm{Cp}$ hydrogens of the reagent being involved in competing hydrogenation and/or $\mathrm{H} / \mathrm{D}$ exchange. ${ }^{45,52,53}$

Next we turned to the aromatic olefin $15 .{ }^{54}$ It seemed logical that $\omega$-functionalised $\alpha$-phenylpropanes would be obtainable from 15 [eqn. (13)]. The postulated intermediate (16) has been shown to give mainly the terminally functionalised product. ${ }^{46}$ The results obtained

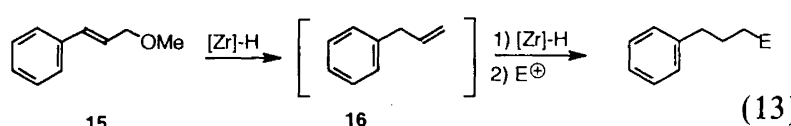

15

16

with 15 were somewhat unexpected. ${ }^{54}$ Although propylbenzene was the major constituent of the reaction mixture, the $\alpha: \omega$ ratio was higher $[\alpha: \omega \approx 4: 6$; eqn. (14)] compared with what had previously been found $\left(\alpha: \omega \approx 1: 9 ; 25^{\circ} \mathrm{C}^{46}\right)$, using 16 as the substrate. At $39-41^{\circ} \mathrm{C}$ the isomer ratio was altered slightly $(\alpha: \omega \approx$ $2-3: 7-8)$.

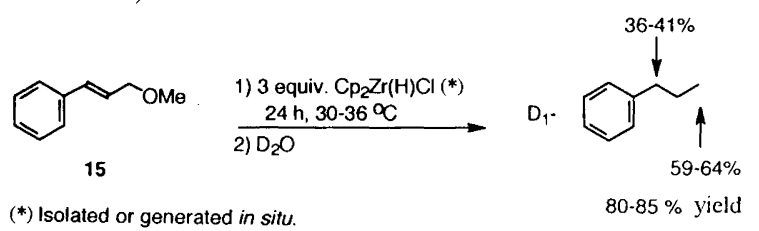

Some experimental evidence for $\mathrm{Cp}_{2} \mathrm{Zr}(\mathrm{H}) \mathrm{OMe}$ [possibly formed via $\beta$-elimination of the ether functionality and subsequent reaction of $\mathrm{Cp}_{2} \mathrm{Zr}(\mathrm{Cl}) \mathrm{OMe}$ with $\left.\mathrm{Cp}_{2} \mathrm{Zr}(\mathrm{H}) \mathrm{Cl}\right]$ being responsible for the high $\alpha: \omega$ ratio [eqn. (14)] was obtained. ${ }^{54}$

Before leaving this section, we present the results obtained with cinnamyl alcohol (17) ${ }^{54}$ We reasoned that the relatively high $\gamma$-selectivity found using oleyl alcohol (Section I), combined with the fact that benzylic zirconium derivatives are stable, should lead to the exclusive formation of 18 [eqn. (15)]. Dehydroxylation was unfortunately more pronounced [eqn. (16)] than in the hydrozirconation of oleyl alcohol.

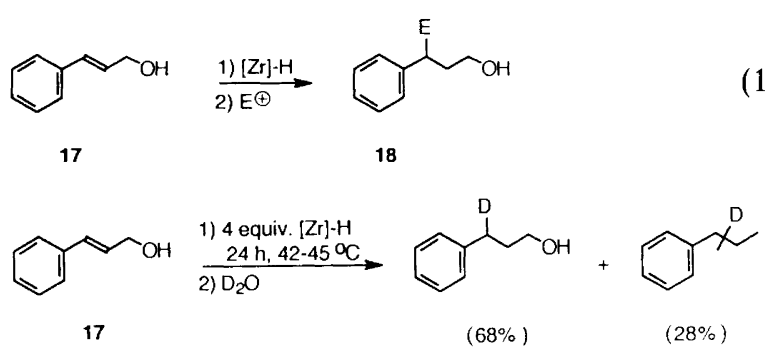

The lactone 19 was prepared in low yield by trapping the benzylic zirconium analogue of 18 with carbon monoxide-iodine.

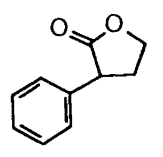

19 
In summary, the results discussed in this section show further limitations of the synthetic utility of hydrozirconation.

III. Experiments with modified zirconocene hydrides. In an effort to enhance the reactivity and improve the regioselectivity with respect to terminal alkylzirconiums, we wanted to make use of a few known zirconocene dihalides for the preparation of modified zirconocene hydrides. ${ }^{55.56}$

$\mathrm{Cp}_{2} \mathrm{Zr}(\mathrm{H}) \mathrm{Br}$ showed no advantages over the chloride analogue, and neither $\mathrm{Cp}_{2} \mathrm{Zr}(\mathrm{H}) \mathrm{F}$ nor $\mathrm{Cp}^{*}{ }_{2} \mathrm{Zr}(\mathrm{H}) \mathrm{Cl}$ $\left(\mathrm{Cp}^{*}=\eta^{5}-\mathrm{C}_{5} \mathrm{Me}_{5}\right)$ could be obtained in the usual way. ${ }^{55}$ ' $\mathrm{Cp}{ }^{*} \mathrm{CpZr}(\mathrm{H}) \mathrm{Cl}$ ' (generated in situ) reacted much faster than $\mathrm{Cp}_{2} \mathrm{Zr}(\mathrm{H}) \mathrm{Cl}$ with $(Z)$ - or $(E)$-5-decene to give 1-deuteriodecane after deuteriolysis. ${ }^{55}$ The rate enhancement is presumably due to the formation of more soluble zirconium hydride(s). Greater solubility is also believed to cause faster reactions of $(\mathrm{MeCp})_{2} \mathrm{Zr}(\mathrm{H}) \mathrm{Cl}$, compared with $\mathrm{Cp}_{2} \mathrm{Zr}(\mathrm{H}) \mathrm{Cl}$, with 1-hexene or acetophenone. ${ }^{57}$

Oleic acid oxazoline (1) (Section I) was converted quite rapidly into the stearyl analogue using ' $\mathrm{Cp}{ }^{*} \mathrm{CpZr}(\mathrm{H}) \mathrm{Cl}$ ' in toluene at $40^{\circ} \mathrm{C}$. No starting material remained after $8 \mathrm{~h}$ and $80 \%$ of the saturated analogue, having a deuterium content of $89 \%$, was isolated upon quenching $\left(\mathrm{D}_{2} \mathrm{O}\right) .{ }^{55}$ The shorter-chain oxazoline shown in eqn. (5) (Section I) was also treated with this modified reagent ( $\approx 20 \mathrm{~h}, 40^{\circ} \mathrm{C}$, dioxane $) .{ }^{56}$ Regardless of the use of different solvents and reaction times, the experiments with these two oxazolines resulted in identical deuterium distribution, but unfortunately the terminal selectivity was even less pronounced than when $\mathrm{Cp}_{2} \mathrm{Zr}(\mathrm{H}) \mathrm{Cl}$ was utilised.

As mentioned in Section II, difficulties were encountered with the aromatic olefin 4 when trying to obtain $\omega$-alkylzirconiums. Even though rate enhancement was observed with $(\mathrm{MeCp})_{2} \mathrm{Zr}(\mathrm{H}) \mathrm{Cl}$, improvement of the $\omega$-selectivity was not achieved. ' $\mathrm{Cp}{ }^{*} \mathrm{CpZr}(\mathrm{H}) \mathrm{Cl}$ ', on the other hand, showed good terminal selectivity at $45^{\circ} \mathrm{C}$ [eqn. 17)]. ${ }^{56}$

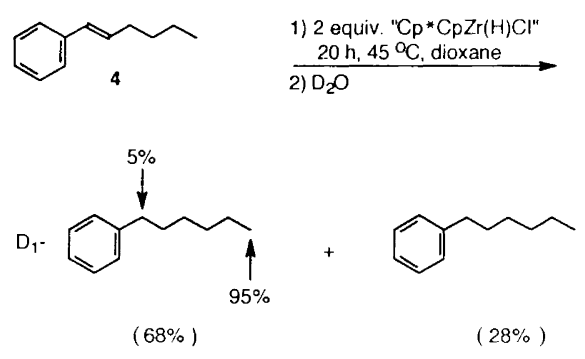

IV. Reactions of alkenes with $\mathrm{Cp}_{2} \mathrm{Zr}(\mathrm{H}) \mathrm{Cl}$. General comments on hydrozirconation-isomerisation. The process [eqn. (2)] has been suggested to proceed via insertion of the olefin into the $\mathrm{Zr}-\mathrm{H}$ bond, followed by rapid eliminations and readditions. ${ }^{7}$ The metal in $\mathrm{Cp}_{2} \mathrm{Zr}(\mathrm{H}) \mathrm{Cl}$ formally has the $\mathrm{d}^{0}$-configuration, and thus the equilibrium in eqn. (18) is shifted to the right by the energy gained from formation of the new $\mathrm{C}-\mathrm{H}$ bond. ${ }^{58}$ If no stabilisation of the secondary $\sigma$-alkylzirconiums can be achieved (cf. previous sections), migration of the metal moiety occurs,

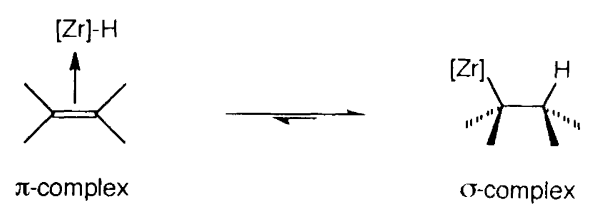

most probably owing to the steric requirements of the $\mathrm{Cp}$ rings. The intrinsic rate of rearrangement to the terminal carbon has been suggested to be at least as fast as insertion of the starting alkene $[(Z)-4$-octene, benzene, room temp.] into the zirconium-hydrogen bond. ${ }^{59}$ This assumption was based on the fact that only starting olefin and the final 1-alkyl compound could be observed when monitoring the reaction by ${ }^{1} \mathrm{H}$ NMR spectroscopy. These observations imply that the metal never dissociates from the hydrocarbon chain, ${ }^{8}$ i.e., path (a) in Scheme 1. Intramolecular rearrangement [parth (a)] has also been indicated in cycloalkylboranes, but it competes with a mechanism corresponding to path (b). ${ }^{60}$ In analogy with alkene complexes of $\mathrm{d}^{0}$-metals (insofar as they exist as intermediates), there should be no stabilising $\pi$-backbonding in the corresponding borane complexes.

In this section we will discuss our observations regarding reactions of alkenes with the zirconium hydride (deuteride), some of which have relevance to Scheme 1.

After hydrozirconation of long-chain ( $Z$ )-olefins, cis-trans isomerisation was often observed. ${ }^{29,39,40}$ The formation of positional isomers of the starting material with the double bond only one or two carbons away from the original position, was indicated by mass spectral analysis, even after quite a long reaction time. ${ }^{29}$ Others too, have found isomerised alkenes using long-chain substrates. ${ }^{46}$ In all these cases, reactions were conducted at slightly elevated temperatures $\left(40-50^{\circ} \mathrm{C}\right)$ with an excess of reagent, as this gave a faster consumption of olefin. As mentioned above, in a previous study ${ }^{59}$ no isomers of the starting alkene were observed during rearrangement.

For a closer look at the process we initially used (Z)-5-decene as a model compound. After reaction in toluene or benzene for $4 \mathrm{~h}$ at $40^{\circ} \mathrm{C}$, the yield of decane never exceeded $70 \%$. The remaining material consisted of isomeric decenes. The rate of alkane formation was considerably higher in THF. Results of the experiments using toluene as the solvent are summarised in eqn. (19). ${ }^{61}$ The
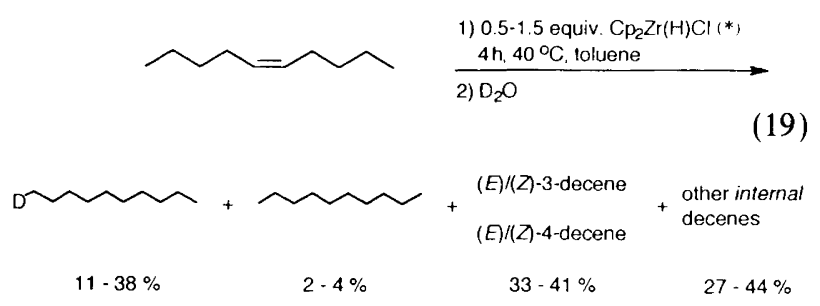

(*) Generated in situ 


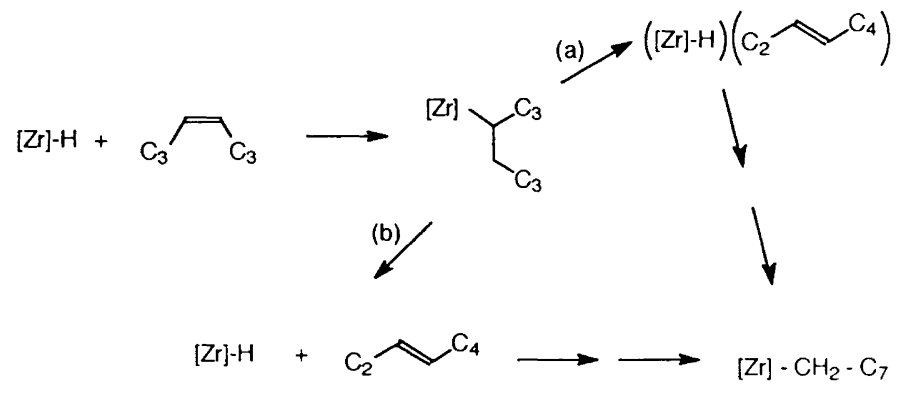

Scheme 1. ${ }^{8}$

yield of decane $\left(11 \% D_{1} ; 4 \% D_{0}\right)$ was significantly lowered using a less than stoichiometric amount of the metal hydride.

Neither 1-decene nor internally deuteriated decane were detected. The isomeric alkenes formed do not stem from the terminal $\sigma$-decylzirconium intermediate (see below), and thus it is obvious that the formation of $\omega$-alkylmetal compound in this case is quite slow.

An interesting point is that only $21 \%$ of $(Z)$-5-decene remained using 0.5 equivalents of $[\mathrm{Zr}]-\mathrm{H}$. A possible reason could be a competing displacement which has been proposed for alkenes and alkynes [eqn. (20)]. ${ }^{62,63} \mathrm{We}$

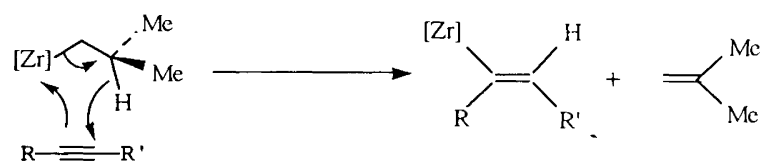

$\mathrm{R}=\mathrm{H}$, alkyl $\mathrm{R}^{\prime}=\mathrm{alkyl}$

conclude, however, that this is not an important sidereaction during hydrozirconation [eqn. (19)]; otherwise (Z)-5-decene would not be unchanged, as it actually is $(\geqslant 97 \%)$, after treatment with about one equivalent of the 1-decylzirconium shown in eqn. $(21) .^{61}$

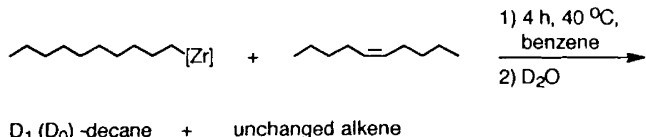

Displacement [eqn. (20)] should result in formation of isomeric decenes from the postulated 5-decylmetal intermediate [compare ordinary hydrozirconation, eqn. (19)]. As can also be seen from eqn. (21), the formation of alkenes from the primary alkylzirconium, via elimination of $[\mathrm{Zr}]-\mathrm{H}$, is unimportant (compare Refs. 7 and 8).

The deuteriozirconation of $(Z)$ - and $(E)$-5-decene (benzene, $40^{\circ} \mathrm{C}, 4 \mathrm{~h}$ ) gave decane with the isotope composition given in eqn. (22). ${ }^{53}$ The deuterium composition in the remaining olefinic mixture varied in the isomers.

Before making any conclusive remarks, we will present a few results concerning alkenes which can give only secondary alkylmetals. ${ }^{61}$ Firstly, alkene 20 was hydrozir-

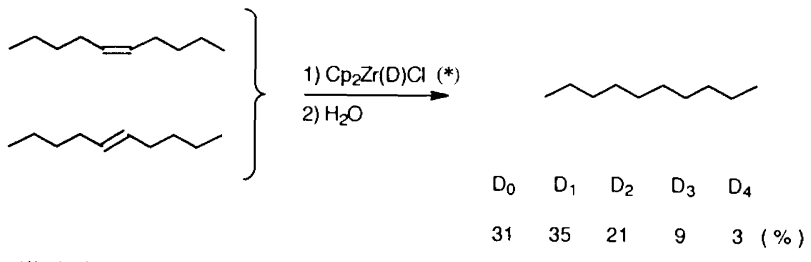

conated [eqn. (23)]. The formation of $\mathbf{2 1}$ was certainly not favoured, independent of conditions. When 20 was treated with $\mathrm{Cp}_{2} \mathrm{Zr}(\mathrm{D}) \mathrm{Cl}$, deuterium was found at several carbons in the alkenes recovered after hydrolysis. Secondly, the reactions of cycloalkenes $\mathbf{2 2}$ and $\mathbf{2 3}$ were studied. Cyclooctene (22) has, like 1-methyl-

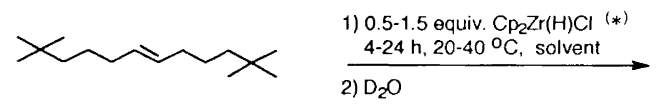

20

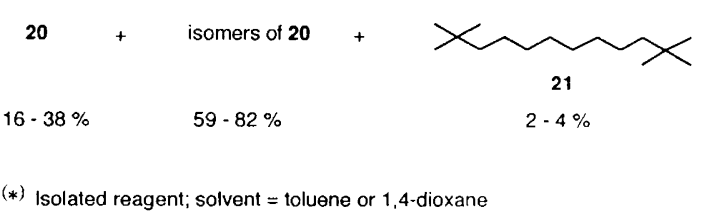

1-cyclohexene (24), been reported not to give any alkyl compounds in hydrozirconation-functionalisation attempts. $^{44,59}$ After deuteriozirconation we recovered $80-100 \%$ of these substrates (Table 1). Even if the cycloalkenes 22 and 23 were not consumed, they were deuteriated with total scrambling. The amount of deuterium incorporated was roughly the same as the amount of $[\mathrm{Zr}]-\mathrm{D}$ used. One might argue that the reason why cyclooctyl- and cycloheptyl-zirconiums are thermodynamically unstable, in contrast with cyclopenty ${ }^{64}$ and cyclohexyl, ${ }^{65,66}$ could be transannular interactions in the former intermediates.

Alkene $\mathbf{2 4}$ was very unreactive. No evidence for deuterium incorporation in the recovered alkene $(80-90 \%)$ was obtained.

As would of course be expected, $[\mathrm{Zr}]-\mathrm{D}([\mathrm{Zr}]-\mathrm{H})$ adds to alkenes 20, 22 and 23 [eqn. (23), Table 1], even if no saturated analogues, or only very small amounts, 
Table $1^{\circ}$

\begin{tabular}{|c|c|c|c|c|c|}
\hline \multirow{2}{*}{$\begin{array}{l}\text { Deuteriozirconated } \\
\text { compound }\end{array}$} & \multirow{2}{*}{$\begin{array}{l}\text { Recovered } \\
\text { olefin }(\%)\end{array}$} & \multicolumn{4}{|c|}{ Isotope composition (\%) } \\
\hline & & $\mathrm{D}_{0}$ & $D_{1}$ & $\mathrm{D}_{2}$ & $D_{3}$ \\
\hline \multirow[t]{4}{*}{20} & $97^{b}$ & $\approx 80$ & $\approx 15$ & $\approx 5$ & \\
\hline & 100 & 33 & 35 & 24 & 7 \\
\hline & $90-95$ & 34 & 36 & 21 & 8 \\
\hline & $80-90$ & 100 & - & - & - \\
\hline \multicolumn{6}{|l|}{24} \\
\hline \multicolumn{6}{|c|}{$\begin{array}{l}\text { The cycloolefins were reacted with } \approx 1 \text { equiv. of } \\
\mathrm{Cp} \mathrm{p}_{2} \mathrm{Zr}(\mathrm{D}) \mathrm{Cl} \text { (isolated) for } 22-23 \mathrm{~h} \text { at } 40^{\circ} \mathrm{C} \text { using } \\
1,4-\text { dioxane as the solvent. Alkene } 20 \text { was deuteriozirconated } \\
{\left[1.0-1.5 \text { equiv. of isolated } \mathrm{Cp}_{2} \mathrm{Zr}(\mathrm{D}) \mathrm{Cl}\right] \text { at the same tem- }} \\
\text { perature for } 4-5 \mathrm{~h} \text { in toluene. With a longer reaction time } \\
(20 \mathrm{~h}) \text { the } \mathrm{D}_{1} \text { and } \mathrm{D}_{2} \text { fractions increased considerably, } \\
\text { corresponding to } 40-50 \% \text {. Analyses were made after } \\
\text { quenching with water. }{ }^{b} \mathrm{Mixture} \text { of isomers. }\end{array}$} \\
\hline
\end{tabular}

were found after quenching. Secondary $\sigma$-alkylzirconiums which are not stabilised (cf. previous sections), are not present in observable amounts when quenching the reactions. This statement is not very unconventional. However, the absence of these zirconium intermediates might not seem completely obvious and requires some further comments on observations pointing in the same direction: $\mathrm{Cp}_{2} \mathrm{Zr}(\mathrm{H}) \mathrm{Cl}$ is a very insoluble material. $\sigma$-Alkylzirconiums are, on the other hand, normally soluble in aromatic solvents, THF, dioxane, etc., and clear solutions, yellow to red in colour, are obtained in reactions where such species can be produced to the extent that the zirconium hydride is consumed. Reactions using $\mathbf{2 0}$ and 22 in excess $(\geqslant 2$ equiv.) never became clear solutions. In the latter case, we did in fact prove the presence of $\mathrm{Cp}_{2} \mathrm{Zr}(\mathrm{H}) \mathrm{Cl}$ in the insoluble residue after 1-2 days at $40^{\circ} \mathrm{C}\{35 \%$ of the starting amount was isolated after $26 \mathrm{~h} ;{ }^{67} \mathrm{IR}$ and ${ }^{1} \mathrm{H}$ NMR $\left.\left[\mathrm{Cp}_{2} \mathrm{Zr}(\mathrm{Cl}) \mathrm{OCH}\left(\mathrm{CH}_{3}\right)_{2}{ }^{68}\right]\right\}$. Furthermore, when 1-decene was treated with a less than stoichiometric amount of the zirconium hydride, hydrogenation was more pronounced compared with when an excess of the reagent was used. ${ }^{61}$ Contrary to what might be expected if secondary alkylzirconiums are present in significant amounts, the formation of $\mathbf{2 1}$ [eqn. (23)] was not favoured using an excess of olefin 20.

The dissociation of the metal hydride from the alkenes during rearrangement [path (b), Scheme 1] is supported by our results. The consumption of nearly $80 \%$ of $(Z)$-5-decene, and $\approx 60 \%$ of 20 , using 0.5 equivalents of $[\mathrm{Zr}]-\mathrm{H}$, together with the exclusion of the displacement shown in eqn. (20) [compare eqn. (21)], points towards dissociation (reasonably, such a displacement [eqn. (20)] from a secondary $\sigma$-complex would not occur either; see above). Dissociation is also implied by the label scrambling and isotope composition in the recovered cycloalkenes (Table 1), and from the isotope composition in decane after deuteriozirconation [eqn. (22)]. It is seemingly contradicted by the large fraction of $\mathrm{D}_{0}$-alkenes $(\approx 80 \%$ ) found upon deuteriozirconation of 20, but this might be due to formation of sterically demanding isomers which are reluctant to react with the reagent. With a longer reaction time the $D_{1}$ and $D_{2}$ fractions increased markedly $(40-50 \%, 20 \mathrm{~h})$.

Acknowledgments. Grants from the Board of Technical Development and from the Swedish Natural Science Research Council are gratefully acknowledged. We also thank Karlshamns AB for financial support.

\section{References}

1. Eisch, J. J. or Zietz, J. R., Robinson, G. C. and Lindsay, K. L. In: Wilkinson, G., Stone, F. G. A. and Abel, E. W., Eds., Comprehensive Organometallic Chemistry, Pergamon Press, Oxford 1982, Vol. 1, pp. 555-682 and Vol. 7, pp. $365-464$, respectively.

2. Eisch, J. J. In: Trost, B. M. and Fleming, I., Eds., Comprehensive Organic Synthesis, Pergamon Press, Oxford 1991, Vol. 8, Chap. 3.11.

3. Smith, K. and Pelter, A. In: Ref. 2, Vol. 8, Chap. 3.10.

4. Brown, H. C. Hydroboration, Benjamin, New York 1962.

5. Brown, H. C. In: Nozaki, H., Ed., Current Trends in Organic Synthesis, IUPAC, Pergamon Press, Oxford 1983, pp. 247-268.

6. Brown, H. C. and Racherla, U. S. J. Organomet. Chem. 241 (1983) C 37.

7. Schwartz, J. and Labinger, J. A. Angew. Chem. 88 (1976) 402.

8. Labinger, J. A. In: Ref. 2, Vol. 8, Chap. 3.9.

9. Riviere, P., Riviere-Baudet, M. and Satgé, J. In: Ref. 1, Vol. 2, pp. 433-434.

10. Armitage, D. A. In: Ref. 1, Vol. 2, pp. 115-120.

11. Stark, F. O., Falender, J. R. and Wright, A. P. In: Ref. 1, Vol. 2, pp. 310-316.

12. Davies, A. G. and Smith, P. J. In: Ref. 1, Vol. 2, pp. 534-535.

13. Hemmer, R. and Unsin, J. In: Methoden der organischen Chemie. Organo- $\pi$-Metallverbindungen als Hilfsmittel in der organischen Chemie, Houben-Weyl, Georg Thieme Verlag, Stuttgart 1986, E 18, Teil 1, p. $664 \mathrm{ff}$.

14. Corey, J. Y. and Zhu, X.-H. Organometallics 11 (1992) 672.

15. Selin, T. G. and West, R. J. Am. Chem. Soc. 84 (1962) 1863.

16. Bruno, G. J. Org. Chem. 30 (1965) 623.

17. Asinger, F., Fell, B. and Warwel, S. Forschungsberichte des Landes Nordrhein-Westfalen, Westdeutscher Verlag GmbH, Opladen 1977, No. 2649, pp. 1-80.

18. Ashby, E. C. and Noding, S. A. J. Org. Chem. 44 (1979) 4364.

19. Sato, F., Sato, S., Kodama, H. and Sato, M. J. Organomet. Chem. 142 (1977) 71.

20. Polivka, Z., Kubelka, V., Holubova, N. and Ferles, M. Collect. Czech. Chem. Commun. 35 (1970) 1131.

21. Polivka, Z. and Ferles, M. Collect. Czech. Chem. Commun. $35(1970) 1147$.

22. Logan, T. J. J. Org. Chem. 26 (1961) 3657.

23. Sisido, K., Naruse, M., Saito, A. and Utimoto, K. J. Org. Chem. 37 (1972) 733.

24. Wipf, P. and Smitrovich, J. H. J. Org. Chem. 56 (1991) 6494.

25. Meunier, P., Gautheron, B. and Mazouz, A. J. Chem. Soc., Chem. Commun. (1986) 424. 
26. Fagan, P. J. and Nugent, W. A. J. Am. Chem. Soc. 110 (1988) 2310.

27. Fryzuk, M. D., Bates, G. S. and Stone, C. J. Org. Chem. 53 (1988) 4425.

28. See for instance Abrams, S. R. Chem. Phys. Lipids 28 (1981) 379.

29. Svenson, R. and Gronowitz, S. Chem. Scr. 19 (1982) 149.

30. Buchwald, S. L., Nielsen, R. B. and Dewan, J. C. Organometallics 7 (1988) 2324.

31. Lappert, M. F., Luong-Thi, N. T. and Milne, C. R. C. J. Organomet. Chem. 174 (1979) C 35.

32. Erker, G. Acc. Chem. Res. 17 (1984) 103

33. Fachinetti, G., Fochi, G. and Floriani, C. J. Chem. Soc., Dalton Trans. (1977) 1946.

34. Ward, A. S., Mintz, E. A. and Ayers, M. R. Organometallics 5 (1986) 1585.

35. Alvhäll, J., Gronowitz, S. and Hallberg, A. Chem. Scr. 25 (1985) 393.

36. Alvhäll, J., Gronowitz, S., Hallberg, A. and Svenson, R. Chem. Scr. 24 (1984) 170.

37. Gibson, T. and Tulich, L. J. Org. Chem. 46 (1981) 1821.

38. Choukroun, R., Gervais, D. and Raoult, Y. Polyhedron 8 (1989) 1758. Also see Ref. 61 and literature cited there.

39. Annby, U., Gronowitz, S. and Hallberg, A. Chem. Scr. 27 (1987) 445.

40. Karlsson, S., Hallberg, A. and Gronowitz, S. Chem. Scr. 28 (1988) 185.

41. Erker, G., Schlund, R., Albrecht, M. and Sarter, C. J. Organomet. Chem. 353 (1988) C 27.

42. Karlsson, S., Hallberg, A. and Gronowitz, S. J. Organomet. Chem 430 (1992) 53.

43. Karlsson, S., Hallberg, A. and Gronowitz, S. J. Am. Oil Chem. Soc. 66 (1989) 1815.

44. Gibson, T. Tetrahedron Lett. 23 (1982) 157.

45. Annby, U., Gronowitz, S. and Hallberg, A. J. Organomet. Chem. 365 (1989) 233

46. Gibson, T. Organometallics 6 (1987) 918.

47. Evans, J., Schwartz, J. and Urquhart, P. W. J. Organomet. Chem. 81 (1974) C 37.

48. Alibrandi, G., Scolaro, L. M., Minitti, D. and Romeo, R. Inorg. Chem. 29 (1990) 3467 and literature cited there.

49. Nelson, J. E., Bercaw, J. E. and Labinger, J. A. Organometallics 8 (1989) 2484

50. See for example, Gronowitz, S., Ed., Heterocyclic Com- pounds. Thiophene and its Derivatives, Wiley-Interscience, New York 1985, Vol. 44, part 1

51. Gronowitz, S. and Frejd, T. Chem. Heterocycl. Compounds 14 (1978) 353.

52. Annby, U., Gronowitz, S. and Hallberg, A. J. Organomet. Chem. 368 (1989) 295.

53. Annby, U. Studies of the Hydrozirconation-Isomerisation Reaction, dissertation, University of Lund, Sweden 1990.

54. Karlsson, S., Hallberg, A. and Gronowitz, S. J. Organomet. Chem. 403 (1991) 133.

55. Alvhäll, J., Gronowitz, S. and Hallberg, A. Chem. Scr. 28 (1988) 285. References concerning the preparation of the zirconocene dihalides, used as precursors, are found in this paper.

56. Annby, U., Gronowitz, S. and Hallberg, A. Acta Chem. Scand. 44 (1990) 862.

57. Erker, G., Schlund, R. and Krüger, C. Organometallics 8 (1989) 2349. Some references regarding other modified zirconocene hydrides are given here (also see Ref. 8, p. 676).

58. Lauher, J. W. and Hoffmann, R. J. Am. Chem. Soc. 98 (1976) 1729.

59. Hart, D. W. and Schwartz, J. J. Am. Chem. Soc. 96 (1974) 8115.

60. Field, L. D. and Gallagher, S. P. Tetrahedron Lett. 26 (1985) 6125 and references cited there.

61. Annby, U., Alvhäll, J., Gronowitz, S. and Hallberg, A. J. Organomet. Chem. 377 (1989) 75.

62. Swanson, D. R., Nguyen, T., Noda, Y. and Negishi, E. J. Org. Chem. 56 (1991) 2590.

63. Negishi, E., Miller, J. A. and Yoshida, T. Tetrahedron Lett. 25 (1984) 3407.

64. Hart, D. W. Transition Metal Hydrides in Organic Synthesis, dissertation, Princeton University 1975, Xerox University Microfilms, Ann Arbor, Michigan 48106.

65. Wailes, P. C., Weigold, H. and Bell, A. P. J. Organomet. Chem. 43 (1972) C 32.

66. Gell, K. I., Posin, B., Schwartz, J. and Williams, G. M. J. Am. Chem. Soc. 104 (1982) 1846.

67. Annby, U. Unpublished work.

68. The ${ }^{1} \mathrm{H}$ NMR analyses of the zirconium hydride were made according to Carr, D. B. and Schwartz, J. J. Am. Chem. Soc. 101 (1979) 3521.

Received May 14, 1992. 